small opening in the vertebra which was caused by the caries. I could not discover any signs of pus in the canal until I removed the posterior ligament. There was no angular curvature or other deformity.

When this patient was first taken ill there was some doubt as to the nature of her case; but when, on the third day, the delirium, sluggish pupil, irregular respiration, cerebral macula, and sulssequently the stiffness in the back and convulsion occurred, inflammation of the brain, probably tuberculous, was diagnosed, though not without some hesitation, on account of the absence of vomiting, throbbing of carotids, extreme heat of head, irregular pulse, retraction of abdomen, \&c., which usually occur in this disease; and it is remarkable that there were no conspicuous symptoms pointing to the spine as the primary seat of lesion. On the first day of her admission she complained of pain in the knees; the cause of this no doubt was irritation of the nerves of the lumbar plexus, probably the obturator, coming off from the cord at the part where the disease was discovered, and the symmetrical expression of the pain indicated, as Mr. Hilton in his lectures on Rest and Pain has proved, the central origin of the exciting cause. The stiffuess in the back was only noticed on one occasion by the nurse, when the patient left her bed and tried to stand. There was no opisthotonos while she was in the recumbent posture, and no tetanic rigidity of the muscles of the extremities. The stiffness was supposed to be produced by extension of the disease downwarda from the membranes of the brain to the cord. Probably some of the venous congestion at the base of the brain, found at the post-mortem, occurred after death; the trunk should have been opened first, as recornmended by Dr. Wilks, in order that all superfluous blood might drain away through the divided cervical vessels. Nevertheless, the absence of a pinkish colour of the white matter and of the puncta vasculosa tends to show that congestion had not occurred to any great extent. The softening and adhesiveness of the pia mater at the base of the brain and cord were well marked, and the deposit of tubercle at one part was so small that doubtless it had nothing to do with the occurrence of the inflammation of the membranes. As far as $I$ an judge, I should say that the disease in the vertebra was of a tuberculous nature on account of the deposit found in the lungs; that it probably commenced in the intervertebral substance; that when the pus formed she was taken ill with the febrile symptoms; the abscess then set up irritation and inflammation of the cord, which extended to the cerebral membranes; and that death took place before there was time for much disorganisation of nerve-substance of cord, which accounted for the absence of paralysis or rigidity of the extremities. This case also is of use in showing the importance of extrems care in the management of a patient of this class-namely, an inmate of a prison, where the greater number of applicntions made to the medical officer are cases of feigned disease in order to avoid punishment or unpleasant work, and if an erroneous opinion is given the whole of the blame falls upon the doctor.

Parkhurst, Isle of Wight.

\section{ABSCESS OF THE RIGHT LUNG BURSTING THROUGH THE DIAPHRAGM AND UMBILICUS.}

BY J. WARING-CURRAN, L.K.\& Q.C.P., L.R.C.S.I., \&c. MEDICAL OFMIOER, MANSFIRLD UNION.

The history of the following case appears to me an exceptional and rare one in practice, and the termination is interesting and unique. The subjoined report is condensed into as concise a form as is compatible with the facts of the case.

H. C-, a stonemason's apprentice, contracted typhoid fever during the last week of February, 1871. The type of the fever was mild, and promised satisfactory crisis until the eighteenth day, when the temperature of the body became unduly elevated, and secondary delirium manifested itself. The patient was restless, tossing off the bed-clothes, and difficult to keep in bed. He continued in this way until the twenty-first day, when a dry, distressing, and constant cough commenced. On the evening of the same day the characteristic rust-coloured sputum of pneumonia was raised. Stethoscopic examination revealed pneumonic engorgement of the lower lobe of the right lung, and, notwithstanding the usual remedies being actively employed, hepatisation followed. On the fifth day from the beginning of the pneumonia, mucous rhonchi became audible at the lateral and posterior part of the right side of the chest, but were accompanied by low delirium, hurried respiration, and extension of pneumonic inflammation upwards. Still there was prunejuice expectoration, free diaphoresis, and regular aetion of the heart. He continued, so to speak, between life and death for four days, sustained by the most powerful stimulants, when the fever began to abate, a sediment formed in the urine, and there was a faint attempt at return of the respiratory murmur in the lowest part of the right lung. The muco-purulent expectoration became excessive, and of conrse the patient was very debilitated; still, in the course of five weeks he was able to leave his bed, but with a fixed pain in the side-the point de côte, -and the expectoration still troubling him and continuing to trouble him throughout the summex months of the year. The boy presented all the outward appearance of tuberculosis; and it would not have been unusual had the lung, affected as it was, broken into tubercular disease. There were but few important auscultatory signs : the breathing on the left side was puevile, and the heart irritable; the upper part of the rigbt lung worked; and a spot corresponding to the fourth rib, marked by a friction-sound, appeared to determine the line of demarcation between the seriously implicated and the more healthy portions of the lung. At this stage the case came to resemble one of empyema-i.e., a case of empyema opening into the lung-texture, and allowing the pus to be expectorated; but there was no enlargement of the diseased side of the chest, nor shifting of vocal sounds with altered positions of the body; and although the londness of mucopurulent râles masked the respiratory murmur, still there was never evidence of its being entirely absent. Nothing approaching agophony was to be detected; indeed, at the angle of the scapula, where we always hear this sound best, the respiratory murmur was fairly distinct.

The boy passed away into the professional care of otber medical men, but returned to me in September, literally worn to a skeleton. When I examined him $I$ found the right lung in much the same condition; and I observed a slight prominence under the edge of the xiphoid cartilage, paiuful to the touch and circumscribed. There was no swelling at the back, nor at the sides of the chest. I directed the swelling to be fomented, \&c. Four days afterwards be experienced a giving way at the prominent point, and, on examining him, I found the swelling had moved and was lower down, to the right, in the sheath of the rectus muscle. Two days later there was a prominence at the umbilicus, resembling a hernial protrusion at this place, which $I$ also directed to be fomented. In the evening of the following day I was hurriedly sent for and found my patient in au apparently sinking condition. His mother had been fomenting the part, when it burst with a "crack," giving exit to an enormous quantity of offensive-smelling pus, which ran out as fluid will through a canula. For some days there was excessive tenderness along the right rectus muscle, and there continued a cupious discharge at the umbilicus (which retained its natural appearance) for fourteen days.

There is no doubt the abscess was pulmonary, for the day it broke the cough decreased in severity and the expectoration diminished in quantity; and that it pointed at, and burst throngh, the triangular interval existing between the sternal and costal portions of the diaphragm, which, as is well known, is only closed at any time by a few triangular muscular fibres and the serous membranes lining the cavities of the chest and abdomen; and that the pus, getting into the sheath of the right rectus muscle, slowly, but not the less surely, worked its way down to the umbilicus, through which it was emptied.

The patient recovered himself by Christmas of last year, and was able to resume his employment early in the spring of the present year. He is now the picture of health and strength, and-with this exception, that I believe the right lung to be adherent to the walls of the chest, especially in that situation where nature allowed the matter to bag against the well-known unprotected space of the dia- 
phragm - nothing the worse for the fearful illness he battled against so successfully, and with so much interest in a professional point of view.

Mansfield.

\section{NEW SELF-RETAINING CATHETER. \\ Bx J. HODGSON WRIGHT, SENIOR SURGEON, HALIFAX INFIRMARY.}

VARious forms of self-retaining catheters have been in nse for some time. I would now bring to the notice of the profession the one represented by the accompanying sketch, and which I have found from more than two years' experience to answer admirably. Its introduction is very simple.

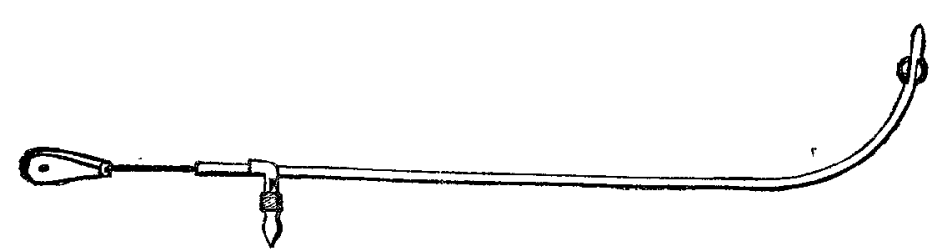

The catheter chosen may be stretched on a steel or soft metal stylet, as the surgeon may judge best. When so stretched that the shoulders of the instrument form no obstruction to its passage, it is tied, and the string passed through the eye in the handle of the stylet, and then fastened, to prevent its springing back into its natural shape. Care must be taken that the stylet is not too large to prevent its moving quite freely within the catheter, and that the end is well rounded, to avoid its penetrating the india-rubber whilst on the stretch. When in the bladder the string is cut and the stylet removed. If the patient has to go about, it is well to cut the catheter short, and apply a small wooden peg, which can be removed at will. It will be necessary to use an instrument sufficiently large to prevent the movements of the patient forcing it out.

The advantages of this catheter, in my opinion, are these-viz., it is easier of introduction in difficult cases, there being no wings to interfere with its manipulation in the urethra should not the right tract have been at once followed, the large-sized opening into the instrument giving easy exit for urine or ropy mucus, and, from its position at the lowest part of the bladder, allowing the last drops to escape more perfectly. It is also impossible for the coats of the bladder to fall upon the opening, and thus impede the flow. It will be found to protrude but a short distance into the bladder, and to cause but little irritation.

The instrument figured is made by Messrs. Weiss, who have been very successful in carrying out my idea. Malifax.

\section{9.}

\section{H O S P T A L P A T T E, BRITISH AND FOREIGN.}

Nulla antem est alia pro certo noscendi via, nisi quamplurimas et morborum et dissectionum historias, tam aliorum, tam proprias collectas habere, et inter se comparare.-MorgagNi De Sed. et Caus. Morb., lib. iv. Procmium.

\section{MIDDLESEX HOSPITAL.}

STRICTURE OF THE URETHRA; ORCHITIS; PY FMIC SYMPTOMS ; PERINEAL SECTION ; RECOVERY.

(Under the care of Mr. HuLke.)

THAT stricture of the urethra is not always the trifling affection that it is frequently supposed to be is fully proved by the following case. Apart from extravasation of the urine, a neglected stricture may become the source of serious and alarming constitutional disturbance, and may, in fact, be the indirect cause of death. There is little doubt that in this case the rigors and the extremely high temperature were in a great measure due to bloodpoisoning; bat the rapid abatement of the graver symptoms after the relief of the stricture by operation seems to show that the local condition had some part in the production of them.

Ed. W- aged thirty, was admitted into the Handel ward on April 9th with swelling and tenderness of the left testicle and epididymis. The patient denied the presence of a urethral discharge, and stated that he had not had gonorrhœa for ten years. Ordered an emetic and purgative mixture to be taken every three hours to purgation and vausea, and to have six leeches applied.

April 11th. - Pain less after the leeches; swelling about the same; tenderness less; bowels freely open ; a constant feeling of nausea yesterday and to-day ; a purulent urethral discharge detected. Ordered an injection of lead to be used frequently; the emetic draught to be omitted.

12th.-Swelling and tenderness less; no evidence of sup puration.

18th. - Swelling and tenderness much diminished; a slight discharge from urethra still present. To have a suspensory bandage.

$22 \mathrm{ad}$-Complains of pains across the loins. Ordered an embrocation consisting of equal parts of opium and soap liniment.

23rd.-The emetic and purgative mixture to be repeated every three hours.-9 P.M. : A rigor set in ; tongue dry and brown.-9.15: Temperature $106^{\prime} 6^{\circ}$ during the rigor; pulse 160, almost imperceptible.-9.20: Temperature 108.4 rigor abating -9.28 : Rigor over ; temperature $108 \cdot 6^{\circ}$; pulse 160.-10: Temperature $105^{\circ}$; pulse 132 ; respiration 32 Tongue moist, coated, red at tip and edges. Urine acid, sp. gr. 1010 , about one-eighth part albumen $-10.20: 0 \mathrm{r}$. dered five grains of sulphate of quinine, to be taken at once.-1050: Rigor returned, and lasted ten minutes. 11.55: Temperature $104.7^{\circ}$; pulse 124. Patient sweating profusely. Bowels relaxed; motions pale and offensive.12: The quinine repeated.

24 th -1 A.M. : Temperature $105 \cdot 6^{\circ}$; at $6,98 \cdot 8^{\circ}$, when five grains of quinine were given -9: A rigor commenced. Temperature $106 \cdot 2^{\circ}$; tongue dry and thickly coated. Or dered ice to suck.-10: Temperature $1056^{\circ}$; to have ten grains of quinine and ten drops of dilute sulphuric acid at once.-3.30 Р M.: Temperature $98.8^{\circ}$; a fifteen-grain dose of quinine given.

25th.-Had a tolerably good night; perspired but little a slight rigor about 5 A.M. Vomited once, and bad bowels opened twice during the night: no jaundice-10: Temperature $101 \cdot 3^{\circ}$; pulse 92 . Complains of painful and frequent micturition.-3 P.M. : Temperature $1048^{\circ}$; quinine repeated. 26 th. -1.30 A.M. : Temperature $106.5^{\circ}$; quinine repeated -9 30 : Temperature normal; quinine repeated, and again at 4 . P.M., when temperature was $103 \cdot 8^{\circ} .-11$ : Temperature $978^{\circ}$.

27th.-5 A.M.: Temperature $104 \cdot 1^{\circ}$; quinine repeated, and again at 10 P.M., when the temperature was exactly the same.

28 th.-The temperature varied from $99.8^{\circ}$ to $103.3^{\circ}$, and the quinine was given once.

29 th - The quinine was given twice, at 10 A.M., when temperature was $1043^{\circ}$, and at 6.30 P.M., when it was $105^{\circ}$. Patient has not had a rigor since the $26 \mathrm{th}$, but complains of frequent micturition and pain at the end of the penis during the passage of the urine, which he cannot retain long; pain and tenderness over the loins. Face pale; no jaundice. Ordered half an ounce of brandy every half-hour. 30th.-A stricture was discovered, and perineal section at once performed; after which the temperature gradually subsided, so that by May 5th it was normal.

May 4th - No urine has passed through the incision for two or three days, but it has passed freely through the catbeter

9th. - Urine alkaline, cloudy, sp. gr. 1006; contains a trace of albumen and some blood-corpuscles.

11th.-Catheter removed, and its end found to be coated with creamy pus. The wound in the perineum is small, healthy, and granulating; tongue clean; appetite good.

12th.-In micturition, more urine flows through the perineal incision than through the urethra.

18 th. - A No. 7 catheter was passed on the $15 \mathrm{th}$, and a No. 8 on the 17th; and on the evening of the latter day he thrice pussed a portion of his urine by the natural passage. 20th.-Brandy diminished to four ounces in twenty-four hours. 